\title{
Reduced carbon monoxide transfer factor (TLCO) in human immunodeficiency virus type I (HIV-I) infection as a predictor for faster progression to AIDS
}

\author{
Richard B Nieman, Judith Fleming, Richard J Coker, J R William Harris, \\ David M Mitchell
}

\begin{abstract}
Background-In addition to the acute fall in carbon monoxide transfer factor (TLCo) associated with Pneumocystis carinii pneumonia (PCP) or other opportunistic lung infections, reduced TLCo occurs in HIV-I seropositive individuals without active pulmonary disease. Abnormal TLCo, in the absence of lung disease, may be a surrogate marker of HIV-I induced immunosuppression and, therefore, a predictor for a more rapid progression to AIDS.

Methods-Eighty four individuals with AIDS, who had regular pulmonary function tests before the diagnosis of AIDS was made, were identified from a cohort of patients with HIV-I infection. None had evidence of active pulmonary disease at the time of initial pulmonary function testing. The relation between the time taken to progress to AIDS and initial pulmonary function tests was examined with life table survival analysis.

Results-Patients with a TLCo value of $<80 \%$ of predicted normal $(n=46)$ progressed significantly faster to AIDS, with a median time of 8.0 months compared with 16.5 months for those with a TLCo value of $\geqslant 80 \%(n=38)$. When stratified by AIDS defining diagnosis (PCP or nonPCP), median time to PCP was also significantly related to initial TLCo values (TLCo of $<80 \%=9.0$ months, TlCo of $\geqslant 80 \%=19.0$ months). Reductions in other measurements of lung function (FEV , FVC, KCo) were not temporally associated with the development of AIDS.
\end{abstract}

Conclusions-HIV-I seropositive individuals with TLCo values of $<80 \%$ predicted and no evidence of lung disease progress more rapidly to AIDS than those with Thco values of $\geqslant 80 \%$.

(Thorax 1993;48:481-485)

The use of simple pulmonary function tests is a non-invasive method of investigating HIV-I infected individuals with respiratory symptoms ${ }^{1}$ and is helpful for assessing the presence and extent of respiratory disease, the need for further investigation, and the response to treatment. ${ }^{2}$ An acute reduction in carbon monoxide transfer factor (TLCO) is the most sensitive test determining lung disease in HIV-I infection and AIDS. ${ }^{3}$ However, it lacks specificity for the development of Pneumocystis carinii pneumonia (PCP), by far the most important pulmonary complication of HIV-I infection, ${ }^{4}$ where a low or falling TLCO has been used as a screening test. ${ }^{3}$ The reduction in TLCO that may occur with PCP is a result of alveolar capillary block ${ }^{5}$ and improves with treatment of the acute episode.

A reduction in TLCO may also occur in HIV-I infection in the absence of overt pulmonary disease. ${ }^{36}$ Lower values of TLCO are seen in patients with more advanced HIV-I disease despite the absence of new pulmonary symptoms or radiographic changes. ${ }^{35}$ The reduction in TLCO in this instance is poorly understood, but has been previously suggested to relate either to a specific HIV mediated alveolitis, ${ }^{78}$ or to reflect pulmonary injury caused by non-specific inflammatory events occurring on a background of HIV induced immunosuppression. ${ }^{9}$ If, indeed, reduced TLCO in HIV-I infection represents compromised pulmonary defence associated with progressive immunosuppression, abnormal results in pulmonary function tests may equate with a worse prognosis and be valuable as a predictor of advancing disease.

In this study we have examined the role of TLCO in HIV-I infection as a marker of disease progression, rather than its more usual role as an indicator of disease presence and severity. We have correlated the length of time to the development of AIDS with initial pulmonary function data obtained after HIV-I seroconversion but before the onset of AIDS, and have shown that a reduced TLCO value identifies a group of patients who progress more rapidly to AIDS.

\section{Methods}

Between 1986 and 1991, all HIV-I seropositive individuals at St Mary's Hospital, London were invited to join a patient cohort to evaluate the long term trends in pulmonary function during HIV-I infection. The vast majority (80-90\%) of seropositive individuals seen at St Mary's Hospital are homosexual/bisexual men. ${ }^{10}$ HIV-I seropositive individuals were recruited to the cohort from the genitourinary medicine outpatient clinic or on discharge from the HIV ward if they 
had been admitted there for investigation or treatment. HIV-I seropositive individuals at all Centre for Disease Control (CDC) ${ }^{11}$ clinical stages up to, and including, AIDS were eligible for enrolment to the cohort. The study was approved by the hospital ethical committee and all patients gave informed consent before participation. Details of the long term changes in pulmonary function that occurred during the study are reported elsewhere. ${ }^{12}$

All individuals from the cohort who had entered at a CDC clinical stage before AIDS, and who subsequently progressed to AIDS, were identified for this analysis. The time interval between initial pulmonary function tests, performed on entry to the cohort at a defined CDC clinical stage, and the development of AIDS was correlated with the results of the pulmonary function tests by life table analysis (Statistical Package for the Social Sciences [SPSS-X]). Median times to the development of AIDS were compared (log rank $\chi^{2}$ ) between patients whose initial pulmonary function test results were either greater than or equal to, or less than $80 \%$ of predicted normal. Predicted values for sex, age, ethnicity, and height were obtained from standard references. ${ }^{13}$ The AIDS defining diagnosis was subclassified to PCP or "nonPCP"- that is, any AIDS defining diagnosis other than PCP (such as Kaposi's sarcoma, cerebral toxoplasmosis).

The demographic details, CDC clinical stage, and smoking habits of the patients were determined at the time of the initial pulmonary function tests. Physical examination and pulmonary radiography were also performed at this time. All patients underwent the following tests: forced expiratory volume in one second $\left(\mathrm{FEV}_{1}\right)$, forced vital capacity (FVC), alveolar volume (VA), and TLCo. The diffusion coefficient (KCO) was derived from the TLCO divided by the VA. Measurements of FEV $_{1}$ and FVC were made with a dry bellows spirometer and the TLCO and VA were determined by the single breath helium dilution method (PK Morgan Transfer Test Model C Machine; PK Morgan, Gillingham, Kent). Corrections for temperature and haemoglobin $^{13}$ were included when calculating values for TLCO, and all measurements were made after a period of at least 30 minutes rest. All smokers were requested to abstain from smoking on the day of their tests. To ensure accuracy of the results over time, the TLCO machine was calibrated daily with standard gases, and to confirm that the equipment was capable of making normal measurements in normal individuals, TLCO values obtained on the dedicated machine used in this study were compared weekly with values of TLCO obtained on a similar machine by the pulmonary function technicians acting as biological disease free controls. The risk of cross infection between patients was reduced by modifications to the equipment as described previously. ${ }^{3}$

All patients who had joined the cohort with reduced TLCO values ( $<80 \%$ predicted normal), respiratory symptoms, or radiographic abnormalities were investigated for an underlying cause by induced sputum analysis or fibreoptic bronchoscopy and bronchoalveolar lavage to obtain specimens for microbiological and cytological investigation. ${ }^{14}$ They were not included in this study if found to have a reduced TLCO because of identifiable pulmonary disease-for example, PCP, pulmonary Kaposi's sarcoma, pneumococcal pneumonia. Patients were similarly excluded if an AIDS diagnosis was made less than one month after the initial pulmonary function tests. By these means we ensured that all patients studied who had a reduced TLCO had no evidence of active or acute pulmonary disease at the time of the initial tests.

\section{Results}

Between 1986 and 1991, 516 individuals with HIV-I infection had pulmonary function tests performed at a defined clinical stage of their HIV-I illness and joined the cohort to evaluate long term changes in pulmonary function. Those in the cohort had risk factors for HIV-I seropositivity that mirrored those of the population seen at St Mary's Hospital during this time. In all, 313 seropositive individuals without an AIDS defining diagnosis joined the cohort and 203 already had AIDS at enrolment. Of the $313 \mathrm{HIV}-\mathrm{I}$ seropositive individuals who joined the cohort before the diagnosis of AIDS, 84 (two women, 82 men) with a mean age of 36.4 (range 23-59) years subsequently developed AIDS and additionally fulfilled the criteria for analysis as described above.

Of these 84 evaluated patients, two were intravenous drug users, 81 were homosexual or bisexual men, and one of the female patients seroconverted after a sexual assault and had no other risk factors for HIV-I infection. The baseline pulmonary function data for the group, expressed as mean (SD) \% predicted normal, were as follows: FVC, 96.8\% (18.2\%); $\mathrm{FEV}_{1}, \quad 102 \cdot 8 \% \quad(19 \cdot 8 \%)$; TLCo, $78 \cdot 3 \%$ (18.7\%); KCO, 87.9\% (16.8\%).

Of the 84 patients, 21 had asymptomatic HIV-I infection (CDC group 2), 25 had persistent generalised lymphadenopathy (CDC group 3 ), and 38 had constitutional symptoms (CDC group 4a). No patients were in CDC group 1 (acute HIV-I infection). Although there was a downward trend in TLCO values for patients in CDC group 2 compared with those in group $4 \mathrm{a}$, the difference was not significant (table 1).

There was no significant difference in the number of smokers $(n=43)$ and non-smok-

Table 1 Mean (SD)\% predicted normal values of TLCO for patients grouped by CDC classification at time of initial pulmonary function tests.

\begin{tabular}{lll}
\hline CDC classification & TLCO & $n$ \\
\hline Group 2 & $83.3(19 \cdot 4)$ & 21 \\
Group 3 & $81.4(17.8)$ & 25 \\
Group 4a & $73.9(18.4)$ & 38 \\
\hline
\end{tabular}


Table 2 Median progression times in months to AIDS related to initial values of $F E V_{1}, F V C, K C O$, and TLCO

\begin{tabular}{|c|c|c|c|}
\hline \multirow[b]{2}{*}{ Initial result } & \multicolumn{2}{|c|}{$\begin{array}{l}\text { Median progression time to } \\
\text { AIDS(months) }\end{array}$} & \multirow[b]{2}{*}{$p$} \\
\hline & $\begin{array}{l}<80 \% \\
\text { predicted }\end{array}$ & $\begin{array}{l}\geqslant 80 \% \\
\text { predicted }\end{array}$ & \\
\hline FVC & $11 \cdot 5(n=11)$ & $9 \cdot 7(n=73)$ & NS \\
\hline $\mathrm{FEV}_{1}$ & $5.5(\mathrm{n}=9)$ & $10 \cdot 1(\mathrm{n}=75)$ & NS \\
\hline Kco & $8.8(\mathrm{n}=27)$ & $10 \cdot 2(\mathrm{n}=57)$ & NS \\
\hline TLCO & $8 \cdot 0(n=46)$ & $16 \cdot 5(\mathrm{n}=38)$ & $\mathrm{p}<0.001$ \\
\hline
\end{tabular}

FVC-forced vital capacity; FEV $_{1}$-forced expiratory volume in one second; Kco-diffusion coefficient for carbon monoxide; TLCo-carbon monoxide transfer factor. $p$ values determined by log rank $\chi^{2}$ test.

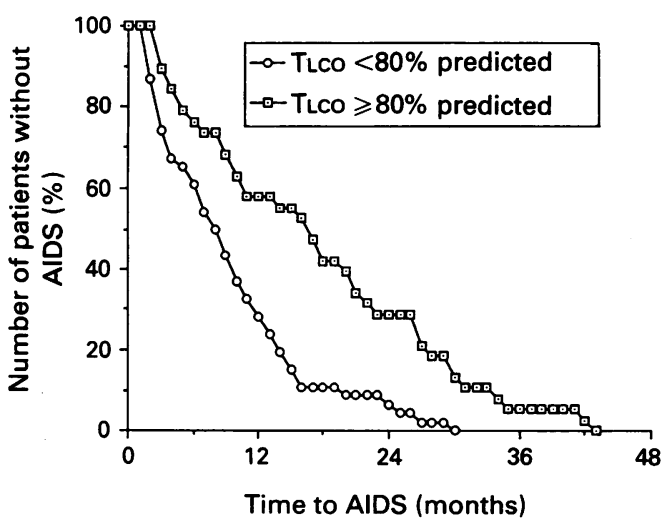

Figure 1 Life table analysis of progression of patients to AIDS related to initial TLCO.

Table 3 Median progression times to AIDS stratified by initial TLCO and by AIDS diagnosis.

\begin{tabular}{llcl}
\hline TLCO (\%) & Diagnosis & $\begin{array}{c}\text { Progression time } \\
\text { (months) }\end{array}$ & $n$ \\
\hline$<80$ & Non-PCP & $8 \cdot 0$ & 16 \\
$\geqslant 80$ & Non-PCP & $10 \cdot 0$ & 18 \\
$<80$ & PCP & $9 \cdot 0$ & 30 \\
$\geqslant 80$ & PCP & $19 \cdot 0$ & 20 \\
\hline
\end{tabular}

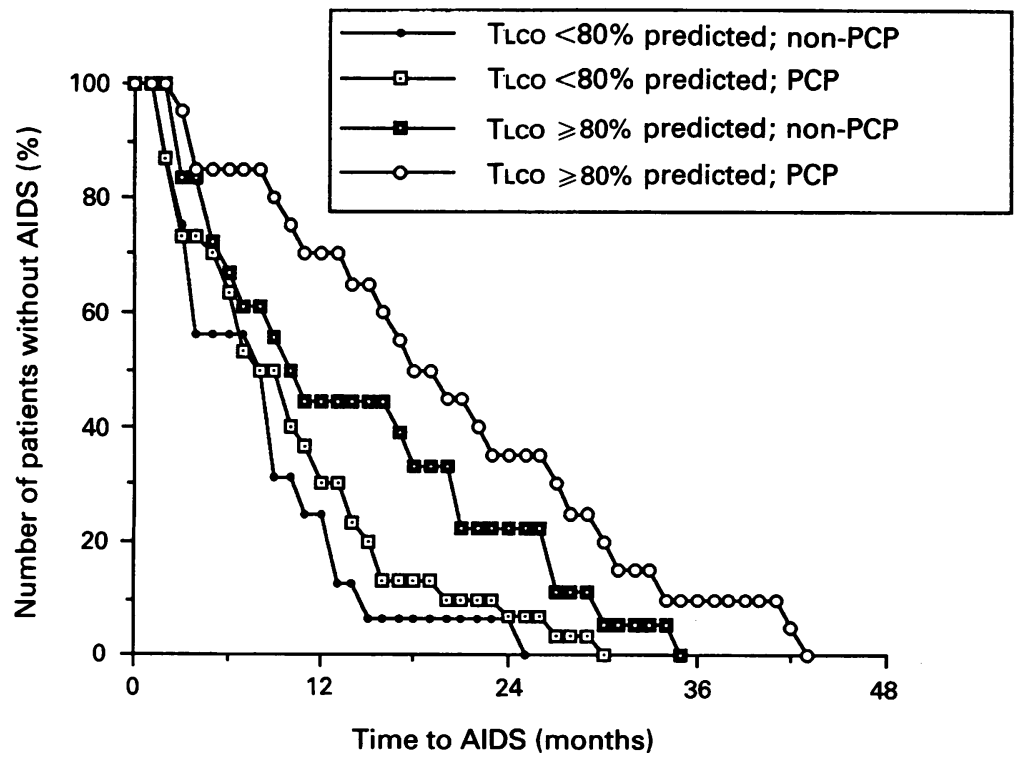

Figure 2 Life table analysis of progression of patients to AIDS stratified by initial TLCO and by AIDS diagnosis (Pneumocystis carinii pneumonia (PCP) or non-PCP). ers $(n=41)$ in each CDC category or in the mean (SD) TLCO values between the two groups at the time of their initial pulmonary function tests (smokers, mean (SD) TLCO = $75.7 \% \quad(16.6 \%)$ predicted; non-smokers, mean (SD) TLCO $=80 \%(20.5 \%)$ predicted; $t$ test, $\mathrm{p}>0.05$ ).

Life table analysis revealed no significant difference in progression time to AIDS when normal and abnormal initial values of $\mathrm{FEV}_{1}$, FVC, or Kco were compared (table 2). Time to progression to AIDS was, however, significantly related to initial TLCO; for patients with TLCO $<80 \%$ predicted, median progression time to AIDS was 8.0 months and for those with TLCO $\geqslant 80 \%$ predicted, median progression time to AIDS was 16.5 months ( $\log$ rank $\chi^{2}, p<0.001$ ) (table 2). Life table curves for patients based on initial TLCO measurements are shown in fig 1.

Of the 84 patients, 50 had PCP as their AIDS defining diagnosis (PCP diagnosis), and 34 had either Kaposi's sarcoma or nonpulmonary opportunistic infections (nonPCP diagnosis). The median time to development of AIDS when caused by PCP was significantly related to initial TLCO values (TLCO $<80 \%$, median progression time to AIDS $=9 \cdot 0$ months; TLCO $\geqslant 80 \%$, median progression time to AIDS $=19.0$ months; $\mathrm{p}<0.005)$. Median time to non-PCP AIDS may relate to initial TLCO values but the trend was not significant (TLCO $<80 \%=8 \cdot 0$ months; TLCO $\geqslant 80 \%=10.0$ months; $p>$ 0.05 ) (fig 2; table 3).

\section{Discussion}

Abnormalities of pulmonary function tests are common in patients with HIV-I infection. ${ }^{13}$ Reduction in TLCO is associated both with PCP and other acute pulmonary diseases, ${ }^{2}$ but occurs also in HIV-I infected individuals without obvious clinical lung disease. ${ }^{312}$ The mechanism for reduced TLCO in HIV-I infection in the absence of overt pulmonary disease is not understood, but does not seem to be due to HIV-I mediated alveolitis, as previously proposed, ${ }^{9}$ nor is it related to the presence of HIV-I in lung macrophages. ${ }^{915}$

When a reduction in TLCO heralds the development of PCP, this reduction is due predominantly to a fall in the membrane diffusion capacity (DM) component of TLCO. This has been attributed to thickening of the diffusion pathway between alveolar gas and pulmonary capillary blood by the attachment of Pneumocystis trophozoites to the epithelial surface-the so-called "alveolar capillary block". ${ }^{5}$ This is in contrast to the chronic reduction in TLCO seen in HIV seropositive individuals who have no evidence of acute or active pulmonary disease. In this case the reduction in TLCO is related to the combination of reduced DM and a reduction in pulmonary capillary blood volume (VC). ${ }^{5}$ In addition, there may be an accompanying fall in KCO and FVC. ${ }^{12}$ This would indicate a product of both reduced diffusion of carbon monoxide and loss of lung volume.

In this study we have shown that a reduced 
TLCO in the presence of HIV-I infection and the absence of lung disease is associated with a more rapid progress to AIDS and, in particular, to the development of PCP. Other pulmonary function measurements which may be abnormal in those who are infected with HIV-I-for example, FEV, FVC, and $\mathrm{KCO}^{16}$ - did not predict the development of AIDS. By excluding all patients who developed AIDS within one month of their initial pulmonary function tests, and by investigating fully those patients with abnormal TLCO and respiratory symptoms or new radiographic changes, we ensured that a reduced TLCO was not related to identifiable pulmonary disease and, in particular, early "smouldering" PCP. The sensitive technique of the polymerase chain reaction has shown that patients without clinical evidence of PCP do not have a positive amplification signal to $P$ carini DNA, ${ }^{1718}$ implying that PCP is a discrete infectious event and is not preceded by an indeterminate prodrome which might lead to a fall in TLCO.

In this study we compared the progression time to AIDS between individuals with pulmonary function of either greater than or equal to, or less than $80 \%$ predicted normal. The cut off point of $80 \%$ was chosen as the value generally accepted to represent the distinction between "normal" and "abnormal" pulmonary function, ${ }^{19-21}$ and the value most often used in descriptive studies of lung function in HIV-I infected individuals. ${ }^{6}$ This is an arbitrary choice and, although this approach has little statistical basis in ascribing normality to pulmonary function, it has the advantage that abnormalities of lung function can readily be classified for individual patients in terms of impairment or disability, and can be appreciated readily by patients and their physicians.

We have recently reported that, in HIV-I seropositive patients without lung disease who have reduced TLCO, pulmonary high resolution computed tomography, technetium$99 \mathrm{~m}$ labelled diethylenetriamine pentaacetic acid ( ${ }^{99 m}$ Tc-DTPA) lung scanning, exercise testing with transcutaneous oximetry, and measurement of both the alveolar membrane component (DM), and pulmonary vascular component (VC) of the TLCO provides no further information as to the cause of the reduction in TLCO. ${ }^{22}$ We have also shown that the detection of HIV-I by the polymerase chain reaction in bronchoalveolar lavage cells has no significant effect on pulmonary function, ${ }^{9}$ arguing against a direct HIV-I alveolitis as the cause of reduced TLCO. In the absence, therefore, of identifiable pulmonary disease such as infection or neoplasm, a low TLCO during HIV-I infection may relate to inflammatory episodes occurring in the lung on a background of advancing immunosuppression..$^{12}$ By reflecting this lung injury, a reduced ThCo may act as a marker of more advanced HIV-I infection. This concept is supported by the previously observed fall in TLCO with advancing immunosuppression, ${ }^{3}$ and would explain the power of TLCO mea- surement in predicting those patients at greater risk of a faster progression to AIDS. Since the KCO did not predict the development of AIDS, it would imply that loss of lung volume-that is, the area available for gas exchange-is the major determinant of the predictive capacity of TLCO.

We have shown, therefore, that a reduced TLCO in HIV-I infection, before an AIDS diagnosis, identifies a group of patients who progress more rapidly to AIDS. This reduction in TLCO during HIV-I infection may represent subtle lung inflammation associated with increasing immunosupression, pathophysiologically different from the acute fall in TLCO during PCP as a result of alveolar capillary block. Further investigation of the potential of TLCO as a surrogate marker of advancing immunosuppression in HIV-I infection is required. Since therapeutic decision making in HIV-I infection (such as when to start zidovudine treatment or chemoprophylaxis for PCP) is commonly made on the basis of deteriorating immunocompetence, ${ }^{23} 24$ the clinical usefulness of TLCO in predicting a more rapid development of AIDS should be compared with established indices of disease progression such as CD4 + cell count and P24 antigenaemia. ${ }^{25}$

The authors wish to thank Jane Wadsworth for statistical advice and Drs Barry Peters and Eddy Beck for their help with data collection

This work was supported in part by a grant from the Jefferiss Research Wing Trust.

1 Coleman DL Dodek PM, Golden JA, Luce JM, Golden $\mathrm{E}$, Gold WM, et al. Correlation between serial pulmonary function tests and fibreoptic bronchoscopy in patients with Pneumocystis carinii pneumonia and the acquired immunodeficiency syndrome. Am Rev Respir Dis 1984;129:491-3.

2 Millar AB, Mitchell DM. Non-invasive investigation of pulmonary disease in patients positive for the human immunodeficiency virus. Thorax 1990;45:57-61.

3 Shaw RJ, Roussak C, Forster SM, Harris JW, Pinching AJ, Mitchell DM. Lung function abnormalities in patients infected with the human immunodeficiency virus with and without overt pneumonitis. Thorax 1988;43:436-40.

4 Murray JF, Garay SM, Hopewell PC. NHLBI workshop summary. Pulmonary complications of the acquired immunodeficiency syndrome: an update. Am Rev Respir Dis 1987;135:504-9.

5 Sankary RM, Turner J, Lipavsky A, Howes EC, Murra JF. Alveolar capillary block in patients with AIDS and Pneumocystis carinii pneumonia. Am Rev Respir Dis 1988;137:443-9.

6 Stover DE, Meduri GU. Pulmonary function tests. In: White DA, Stover DE eds. Pulmonary effects of AIDS. Clin Chest Med 1988;9:473-9.

7 Suffredini AF, Ognibene FP, Lack EE, Simmons JT, Clifford-Lane H, Fauci AS, et al. Non-specific interstitial pneumonitis: a common cause of pulmonary disease in the acquired immunodeficiency syndrome. Ann Intern Med 1987;107:7-13.

8 Guillon JM, Autran B, Denis M, Fouret P, Plata F, Mayaud CM, et al. Human immunodeficiency virus related lymphocytic alveolitis. Chest 1988;94:1264-70.

9 Clarke JR, Fleming J, Donegan K, Moss FM, Nieman R, Williamson JD, et al. Effect of HIV-1 and cytomegalovirus in bronchoalveolar lavage cells on the transfer factor for lung carbon monoxide in AIDS patients. AIDS 1991;5:1333-8.

10 Peters BS, Beck EJ, Coleman DG, Wadsworth MJH, McGuinness O, Harris JRW, et al. Changing disease
patterns in patients with AIDS in a referral centre in the patterns in patients with AIDS in a referral centre in the

11 Center for Disease Control. Classification system for HIV infections. Morbidity and Mortality Weekly Report 1986; 35:334-9. 
12 Mitchell DM, Fleming J, Pinching AJ, Harris JRW, Moss FM, Veale $\mathrm{D}$, et al. Pulmonary function in human immunodeficiency virus infection: a prospective eighteen month study of serial lung function in 474 patients. Am Rev Respir Dis 1992;146:745-51.

13 Cotes JE. Lung function: assessment and application in medicine. 4th ed. Oxford: Blackwell Scientific Publications, 1979.

14 Millar RF, Leigh TR, Collins JV, Mitchell DM. Tests giving an aetiological diagnosis in pulmonary disease in patients with the human immunodeficiency virus. Thorax 1990;45:62-5.

15 Clarke JR, Krishnan V, Bennett J, Mitchell DM, Jeffries DJ. Detection of HIV-1 in human lung macrophages using the polymerase chain reaction. AIDS 1990; 4:1113-36.

16 Murray JF, Mills J. Pulmonary infectious complications of human immunodeficiency virus infection (part 1). $A m$ Rev Respir Dis 1990;141:1356-72.

17 Wakefield AE, Pixley FJ, Banerii S, Sinclair K, Miller RF Moxon ER, et al. Detection of Pneumocystis carinii with DNA amplification. Lancet 1990;336:451-3.

18 Wakefield AE, Guiver L, Miller RF, Hopkin JM. DNA amplification on induced sputum samples for diagnosis of Preumocystis carinii pneumonia. Lancet 1991;337: of Pneumo

19 Coates JE. Predicted values: how should we use them? Thorax 1989;44:240.

20 American Thoracic Society. Evaluation of impairment/disability secondary to respiratory disorders. Am Rev Respir Dis 1986;133:1205-9.

21 Wanger J. Pulmonary function testing: a practical approach. Baltimore: Williams and Wilkins, 1992.

22 French PD, Cunningham DA, Fleming J, Donegan C, Harris JRW, Shaw RJ, et al. Low carbon monoxide transfer factor (TLCO) in HIV-infected patients without lung disease. Resp Med 1992;86:253-6.

23 Swart AM, Weller I, Darbyshire JH. Early HIV infection: to treat or not to treat? $B M \mathcal{F} 1990 ; 301: 825-6$.

24 Girard PM, Pocidalo J, Murray JF. Primary prophylaxis against common infectious diseases in persons with human immunodeficiency virus infection. Am Rev Respir Dis 1991;143:447-50.

25 Mitchell DM, Miller RF. Recent developments in the management of the pulmonary complications of HIV disease. Thorax 1992;47:381-90. 